\title{
Mite Fauna Investigation Followed by Environmental Improvement Is Essential In Treating Intractable Atopic Dermatitis
}

\author{
Hideo Nakayama ${ }^{1 *}$, Akiko Kumei ${ }^{1}$, KoRon Chen ${ }^{1}$ and Masatoshi Takaoka ${ }^{2}$ \\ ${ }^{1}$ Meguro Chen Dermatology Clinic \\ ${ }^{2}$ Pest Management Laboratory
}

\begin{abstract}
There is enough accumulated evidence to conclude that house dust mites (HDM) are the most significant causes of atopic dermatitis (AD). HDMs are known to increase serum IgE and RAST scores for Dps and Dfs, and will often show positive results among AD patients when a patch test using three crushed HDMs or many HDMs in a petrolatum-base is performed.

However, HDMs are invisible to the naked eye as they measure less than $0.3 \mathrm{~mm}$, and therefore even when thousands of HDMs are present in the interior of the patients' homes, they live quietly without causing any noise, and therefore their presence cannot be detected by the patients.

The newly developed Methylene Blue Agar method (MBA) can reveal how many HDMs are present in each interior object, and through this method, they can be reduced to less than $50 / \mathrm{m} 2 / 20$ seconds aspiration for all interiors, dramatically improving severe symptoms of AD for patients who have even suffered for more than ten years. Therefore, it is critical that the mite fauna of the patients' home is examined so that effective measures can be taken to cure the patient. Consequently, AD considered as a unique form of allergic contact dermatitis due to the fact that HDMs involve both type I and type IV allergies. Please note that the rare exceptions are $\mathrm{AD}$ caused by reactions towards metals and the malassezia group fungi.
\end{abstract}

\section{Introduction}

Providing evidence is crucial when identifying the causes and the cure rate for the treatment of intractable allergic diseases. Mild atopic dermatitis $(\mathrm{AD})$ can easily be treated through anti-symptomatic treatment composed of corticosteroid ointments and perorally administered antihistamines. However, with severe cases, such antisymptomatic treatments can temporarily improve the symptoms of $\mathrm{AD}$, but the frequent recurrence of eczema is so common that the patients suffer from itchy dermatitis on their entire body. This can result in generalized erythroderma or acanthotic eczema of flexor surfaces of the extremities and the face for many years. The presence of severe itching leads to a lower quality of life, especially when exudation from the eczema is prominent and staphylococcal secondary infection worsens the disease. Fortunately, much evidence has been accumulated as to the true and main causations of the $\mathrm{AD}$, even though $\mathrm{AD}$ is multifactorial and a variety of abnormalities have been known. Here is the report that the main causations of intractable and severe $\mathrm{AD}$ are house dust mite allergy, and the fact that mite fauna investigation of the patients' homes followed by correction of the interior of the homes to improve the mite rich places are an excellent solution of the problem. We have to remember that the main and crucial causations of intractable $\mathrm{AD}$ are the patients' own houses, and they can be cured through correct mite fauna investigation accompanied by the action to scientifically decrease the mite numbers of their homes to maintain the improved skin conditions.

\section{Evidence of the causation (1): IgE RAST and patch test results}

Genetically AD patients from infants have been known to have insufficient skin surface barrier. The main reason is that the amount of filaggrin in the horny layer is not sufficient [1]. Therefore, many kinds of contact allergens can easily penetrate into the skin, so that multifactorial allergy is inevitably produced. This condition can be compared to that of a house with which the windows and doors are always open, so that thieves freely intrude to perform robbery. The important fact here is that the actions of the robbery were performed by the thieves who intruded, and not by the open windows and doors.

The responsibilities of Dermatophagoides pteronyssinus (Dp), one of the common house dust mites (HDM), for the production of atopic asthma were reported for the first time by Voorhorst et al in 1969 [2]. In 1967, Ishizaka et al discovered serum IgE, as a serum immunoglobulin

Correspondence to: Hideo Nakayama, Meguro Chen Dermatology Clinic Shinyo-CK Building 6F 3-3-5, Kami-Ohsaki, Shinagawa-ku, Tokyo 141-0021, Japan, Tel: +81-3-3786-1678; E-mail: nakayamadermatology@eos.ocn.ne.jp

Key words: atopic dermatitis, house dust mite (HDM), mite allergy, dermatophagoides, mite elimination

Received: February 10, 2018; Accepted: February 16, 2018; Published: February 20, 2018 
associated with atopic diseases [3]. Johansson discovered that serum IgE is markedly elevated among AD patients as well [4].

Okudaira et al $[5,6]$ discovered that serum IgE levels are usually less than $1,000 \mathrm{IU} / \mathrm{ml}$ with bronchial asthma, allergic rhinitis and urticaria, however, when the patients suffer from eczema of the skin at the same time, IgE levels easily exceeded 2,000 IU/ml. When this tendency was re-examined at the Nakayama Dermatology Clinic where many allergic patients gathered, the results are shown in the Table 1 [7]. As is demonstrated, the tendency that the presence of eczema of $\mathrm{AD}$ was the most decisive factor to increase serum IgE level increase, and the absence of eczema showed much less levels of IgE levels among other three allergic diseases.

In 1984, Rawle et al [8] reported the presence of delayed type hypersensitivity to HDM components. They found that the P1 allergen of $\mathrm{Dp}$, in another term Der P1, produced cytotoxic effects in $\mathrm{AD}$ and $\mathrm{AD}+$ asthma patients. IgE levels were independent for this type of allergic reaction. This result suggested the presence of contact hypersensitivity to HDM among AD patients. Therefore, HDMs, Dps and Dermatophagoides farinae (Dfs), were cultured in a hospital, and three live mites were captured under a microscope, crushed on slightly convex plastic plates, and were patch tested on the backs of $\mathrm{AD}$ patients and controls for two days, and the reactions were read on the second, third and seventh day by ICDRG standards. This was necessary because the same three dead and dry mites showed no positive reactions when patch tests were performed in a similar manner previously (Table 2). As already reported, only three live mites produced clear positive patch test reactions with mainly $\mathrm{AD}$ patients, showing that some chemicals present in live mites and not present in dead and dry mites have produced erythema, papules, vesicles with itching just like the original AD (Figure 1) $[9,10]$. Its histopathology of patch test positive reactions showed spongiotic vesicles in the epidermis with lymphocytic infiltration of the upper dermis, just like that of an ordinary allergic contact dermatitis (Figure 2).

Bruynzeel-Koomen et al, on the other hand, made a great discovery that Langerhans cells in the epidermis wear IgE molecules on the surface to provoke eczema, when mite protein come into contact from the environment [11]. Novak et al confirmed this phenomenon, establishing a link between serum IgE antibodies and eczematous reactions of $\mathrm{AD}$ [12]. Therefore, there are two kinds of mechanisms for AD patients to provoke eczematous skin reactions. Firstly through ordinary contact allergic reactions demonstrated by a patch test, without the effect of serum IgE molecules. The second mechanism requires serum IgE molecules to be conjugated on the surface of epidermal Langerhans cells to produce eczematous reactions, when these IgE molecules have contact to airborne antigens, such as HDM, malassezia, staphylococcus etc. Seidenari et al cultivated a number of

Table1. Serum IgE levels of four allergic diseases, demonstrating that atopic dermatitis shows remarkable high levels of IgE compared to other atopic diseases without eczema [7].

\begin{tabular}{|c|c|c|c|c|c|c|}
\hline & \multirow{2}{*}{ Diseases } & \multirow{4}{*}{$\begin{array}{c}\mathbf{n} \\
(\mathbf{M}, \mathbf{F}) \\
83 \\
(24,59)\end{array}$} & \multicolumn{2}{|c|}{$\operatorname{IgE}(\mathrm{IU} / \mathrm{ml})$} & \multicolumn{2}{|c|}{ Age } \\
\hline & & & mean & SD & \multirow{3}{*}{$\begin{array}{c}\text { mean } \\
23.9\end{array}$} & \multirow{3}{*}{$\begin{array}{l}\text { SD } \\
8.3\end{array}$} \\
\hline \multirow{2}{*}{1} & \multirow{2}{*}{ Atopic dermatitis } & & \multirow{2}{*}{$2,947.3$} & \multirow{2}{*}{$5,404.5$} & & \\
\hline & & & & & & \\
\hline \multirow{2}{*}{2} & \multirow{2}{*}{ Bronchial asthma } & 18 & \multirow{2}{*}{336.5} & \multirow{2}{*}{439.8} & \multirow{2}{*}{43.1} & \multirow{2}{*}{22.6} \\
\hline & & $(3,15)$ & & & & \\
\hline \multirow{2}{*}{3} & \multirow{2}{*}{ Allergic rhinitis } & 53 & \multirow{2}{*}{323.8} & \multirow{2}{*}{617.1} & \multirow{2}{*}{42.5} & \multirow{2}{*}{17.1} \\
\hline & & $(11,42)$ & & & & \\
\hline \multirow{2}{*}{4} & \multirow{2}{*}{ Urticaria } & 54 & \multirow{2}{*}{350.9} & \multirow{2}{*}{678.4} & \multirow{2}{*}{45.5} & \multirow{2}{*}{19.3} \\
\hline & & $(20,34)$ & & & & \\
\hline
\end{tabular}

HDMs and performed patch testing with fresh multiple HDMs mixed in petrolatum [13]. It was a good invention because later, patch tests using three live HDMs became unnecessary, because these freshly packed HDMs in tubes kept enough ability to provoke clear positive allergic reactions when these allergens were patch tested on Finn Chambers for two days on the backs of the patients. This type of patch test reagents have been commercially sold by the Chemotechnique Company in Sweden.

There are multiple allergens that raise serum IgE levels, and the responsibilities to raise IgE levels of each allergens can be shown by
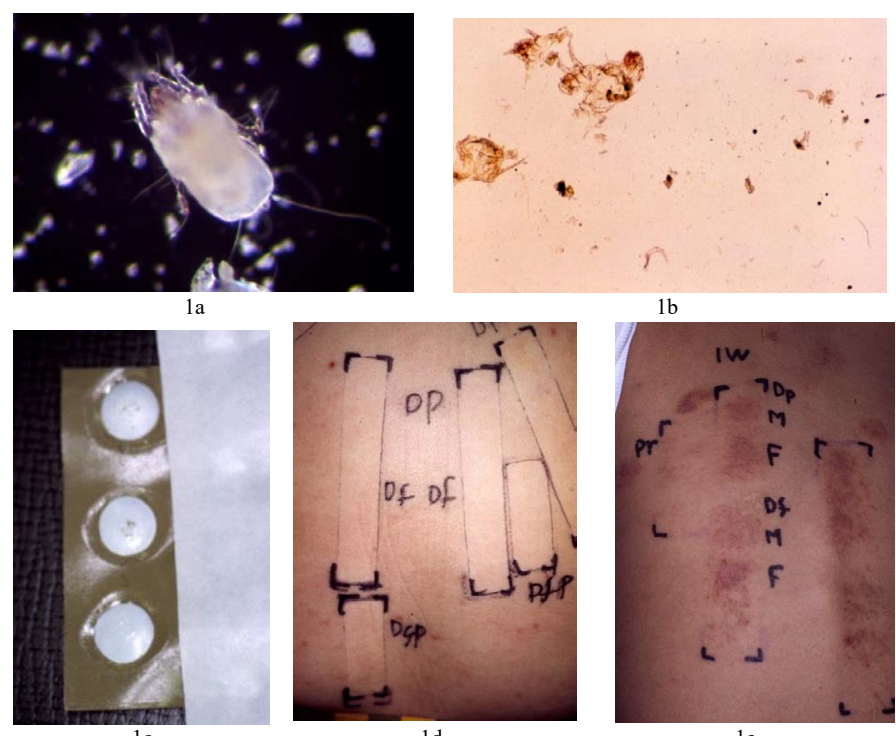

Figure 1. Cultured live Dermatophagoides pteronyssinus (Dp, female) (1a). Three live mites (Dps and Dfs. males and females) were crushed on convex plastic plates of $8 \mathrm{~mm}$ in diameter for patch testing (1b). Fine dots on the upper two plates are crushed male Dps and female Dps respectively. The third plate is a control without mite fragments (1c). Controls showed negative reactions (1d), whereas a 2 -year-old $A D$ patient showed clear positive reactions from the third day of the patch test. Positive reactions in two rows with the same arrangements of mite allergens on the seventh day of the test show that the allergic reactions are reproducible, and they could produce itchy eczematous reactions (1e).

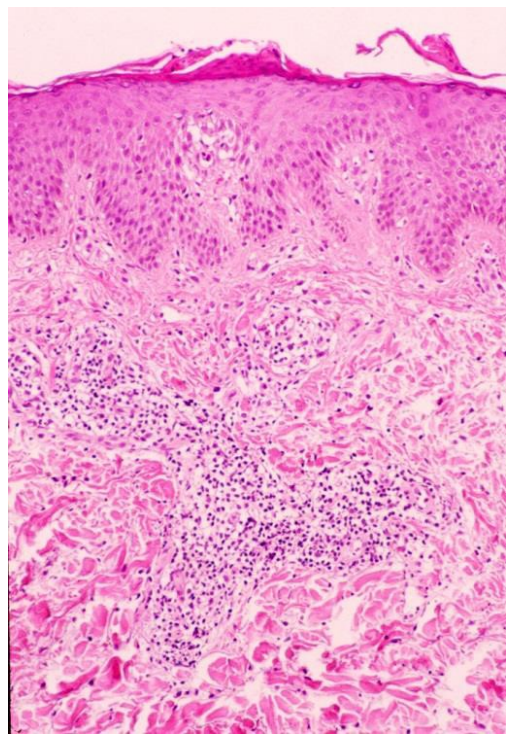

Figure 2. Histopathology of positive reactions to three live Dps or Dfs showed spongiosis of the epidermis and mononuclear cell infiltration of the upper dermis, a typical finding of ordinary allergic contact dermatitis. 
Table 2. The positive reaction rate with three crushed live and dead, dry Dermatophagoides (Dp \& Df) patch test [7] .

\begin{tabular}{|c|c|c|c|}
\hline & live Dps & live Dfs & Blank \\
\hline Atopic dermatitis & $25 / 73=34.2 \%$ & $10 / 45=22.2 \%$ & $0 / 49=0 \%$ \\
\hline $\begin{array}{c}\text { Control } \\
\text { (Non-AD dermatitis) }\end{array}$ & $2 / 36=5.6 \%$ & $0 / 18=0 \%$ & $0 / 24=0 \%$ \\
$0 / 7=0 \%$ & $0 \%$ \\
\hline
\end{tabular}

$(2+)$ and $(+)$ reactions by ICDRG standards were considered as being positive.

\begin{tabular}{lcc}
\multicolumn{1}{c}{ Allergens } & UA & $\%$ \\
\hline $\begin{array}{l}\text { Dermatophagoides } \\
\text { pteronyssinus }\end{array}$ & 127 & 87.0 \\
$\begin{array}{l}\text { Fungi (3 kinds) } \\
\text { Japanese cedar pollen }\end{array}$ & 5 & 3.4 \\
Food (10 kinds) & 6 & 4.1 \\
\hline \multicolumn{1}{c}{ Total } & 146 & 100.0 \\
\multicolumn{2}{c}{$\begin{array}{l}\text { n=42 (17 males and } 25 \text { females }) \\
\text { Average age }: 23.5 \text { years old }\end{array}$} \\
\end{tabular}

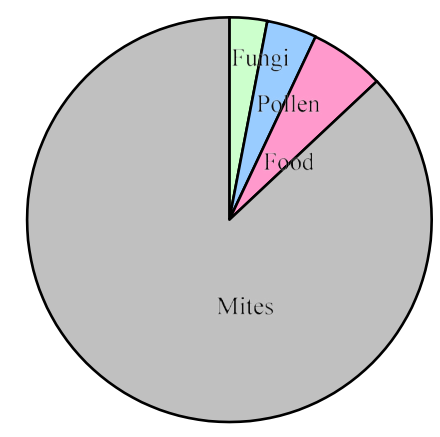

3a Responsibilities of various allergens for serum IgE elevation investigated by the serum dilution method on 42 adult $\mathrm{AD}$ patients (1991)

\begin{tabular}{lcc}
\multicolumn{1}{c}{ Allergens } & UA & $\%$ \\
\hline $\begin{array}{l}\text { Dermatophagoides } \\
\text { pteronyssinus }\end{array}$ & 340 & 77.2 \\
$\begin{array}{l}\text { Fungi (3 kinds) } \\
\text { Japanese cedar pollen }\end{array}$ & 32 & 7.3 \\
Food (10 kinds) & 53 & 14.4 \\
\hline \multicolumn{1}{c}{ Total } & 440 & 100.0 \\
\multicolumn{2}{c}{$\begin{array}{l}\text { n=42 (28 males and 14 females) } \\
\text { Average age : } 29.8 \text { years old } \\
\text { Average serum IgE level : } 6,751 \mathrm{IU} / \mathrm{ml}\end{array}$}
\end{tabular}

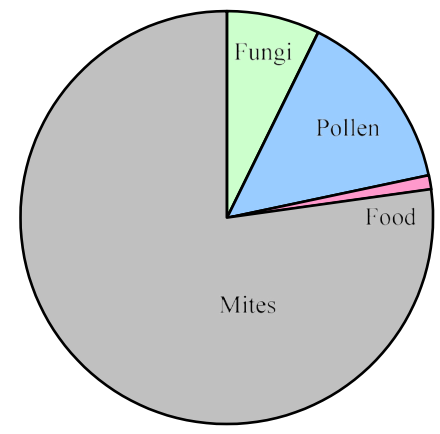

$3 \mathrm{~b}$ Responsibilities of various allergens for serum IgE elevation investigated by the serum dilution method on 42 adult $\mathrm{AD}$ patients (2006)

Figure 3. The rates of responsibilities of allergens were calculated from the values of UA of RAST investigated from 42 severe cases of atopic dermatitis. 1a is the result obtained in 1991, showing that in average, $87.0 \%$ of elevated serum IgE can be attributed to Dermatophagoides. $1 \mathrm{~b}$ is the result obtained in 2006 from similar severe cases of atopic dermatitis of the same number, showing that in average, $77.2 \%$ can also be attributed to Dermatophagoides. Note the increase in the rate of cedar pollens on the production of IgE in 2006 , and yet, the responsibility of Dermatophagoides is still very high in the elevated serum IgE with 42 severe atopic dermatitis patients [10].

the unit of allergy (UA) today. The IgE amount that reacts to a certain allergen is indicated by UA values, when possible cross reactions are eliminated. For example, when the UA of Dp is adopted and that of Df is deleted, malassezia is adopted and pityrosporum is deleted, it is possible to calculate the percentage of the responsibilities of each allergen in the increased serum IgE levels. The results were obtained when 42 severe AD patients were investigated in the late 1990s and after the new millennium (Figure 3). These results showed that the responsibility of Dp was $87 \%$ in the 1990 s, and $77 \%$ after the new millennium. The decrease in the later study is apparently due to the continual increase in the Japanese cedar pollens in the spring time after the new millennium. Yet it was quite clear that when there is a severe $\mathrm{AD}$ patient whose serum IgE was $2,000 \mathrm{IU} / \mathrm{ml}$, on average $1,400 \mathrm{IU} / \mathrm{ml}$ (70\%) or more was due to Dps in his or her own house. Considering the elevation of serum $\operatorname{IgE}$ is unique to $\mathrm{AD}$, and the link of elevated $\operatorname{IgE}$ and eczema has been clarified $[11,12]$, it must be erroneous to consider that the main allergens are other than Dermatophagoides.

Even when three crushed live mites exhibited clear eczematous reaction on $\mathrm{AD}$ patients, standard HDM proteins often showed negative results. This phenomenon meant that there must have been causative HDM allergens other than mite proteins, such as Der 1 or 2. Usually, eczematous allergic reactions are provoked by the contact of simple chemicals with molecules less than $500 \mathrm{KD}$. Therefore, after the contact allergenicity to HDM was established, such simple chemicals with molecules less than $500 \mathrm{KD}$ were tried to be detected using cultured HDMs. Two groups initiated this work in Japan when national research teams started investigating the causation and 

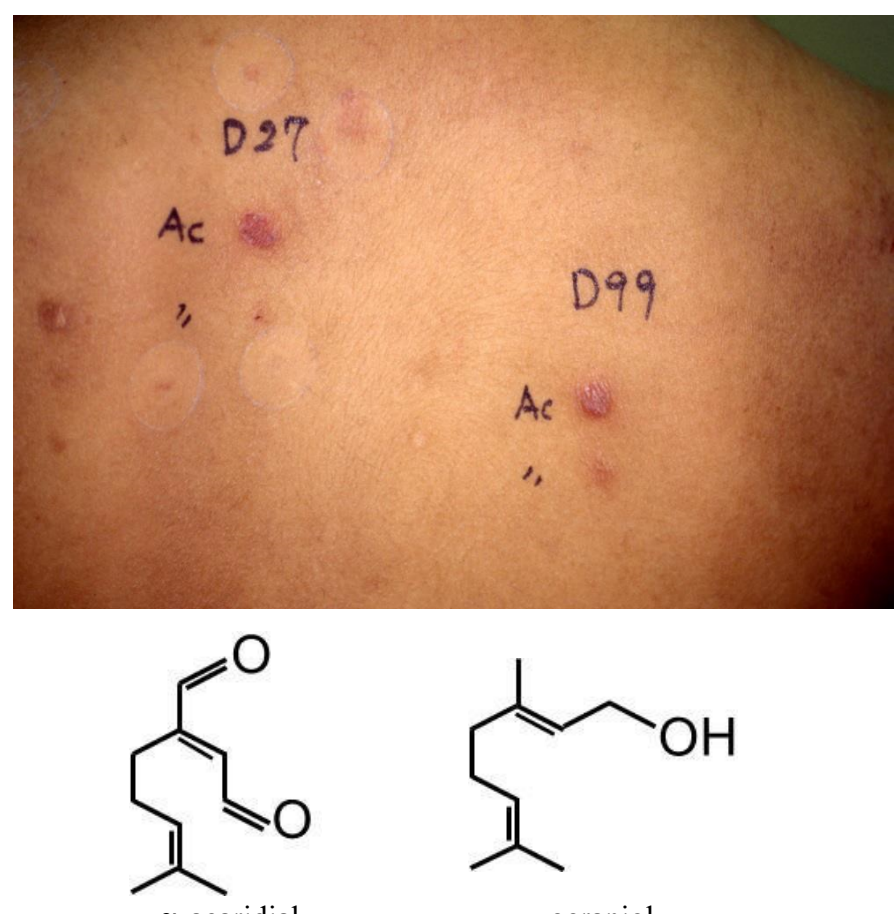

$\alpha$-acaridial

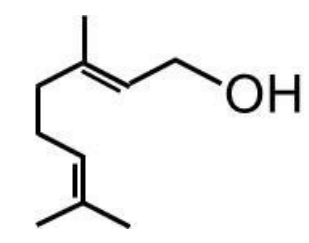

geraniol

Figure 4. $\alpha$-acaridial was found to produce long term positive reactions when patch tested at $0.2 \%$ to $1.0 \%$ in petrolatum. The reaction simulated prurigo nodule clinically, and lasted 6 months at the longest. Fig.4 shows such a long term positive reaction on the 99th day of the patch test (right side) on a 20 -year-old female AD patient. Confirmative patch test again produced a long term positive reaction (left side), which was still positive on the 27th day. This extraordinary prurigo like allergic reaction supposedly occurs because $\alpha$-acaridial is not destroyed in the upper dermis to stay for many days, as in the case of salicylanilides with persistent light reaction [27].

treatment of AD in 1989. The group of Sakurai et al cultured a number of HDMs, Dps and Dfs and the mites were collected, extracted by Folch Solution with mite components. The analysis using gas chromatograph mass spectrometry revealed that the presence of geraniol / geranial as the most rich terpenes, with the rate of $0.04 \%$ [14]. Culture medium without mites were also extracted in the same way as the controls and it did not show the presence of geraniol / geranial.

Kuwahara's group picked up 40 mites from the culture, and these mites were put into hexane, then the mite body components were analyzed through gas chromatograph mass spectrometry. They found the presence of 80 simple chemicals and again geraniol / geranial was the most rich component among terpenes [15, 16]. Geraniol and geranial are similar components and usually they are present in ordinary soaps, shampoos and cosmetics. The amount of these terpenes were considered to have been much less when there was only a small number of HDMs present in ordinary living conditions. Mite fauna investigation, however, rarely demonstrated unbelievably large number of HDMs in the patients' homes, when idle patients did not clean the rooms for months. In such extraordinary cases, the amount of geraniol / geranial in pillows or sleeping mats might have reached to provoking the threshold of eczema. Table 3 shows the reactivities of these terpenes in HDMs in $\mathrm{AD}$ and ordinary contact dermatitis.

Kuwahara et al discovered the presence of $\alpha$-acaridial in the terpenes from the Tyrophagus putrescentiae (Tp) they studied [16, 17]. When synthesize $\alpha$-acaridial was evaluated by patch testing in concentrations ranging from $0.2 \%$ to $1.0 \%$, it turned out to have been a very strong sensitizer. Positive patch test reactions started to appear from the second to tenth day of the patch test showing erythema,

infiltration with itching. The positive reactions remained for 1 to 3 months, and 6 months at the longest (Figure 4). Histopathology showed acanthosis of the epidermis and lymphocytic infiltration of the upper dermis was mainly composed of $\mathrm{CD}-4$ positive $\mathrm{T}$ lymphocytes (Figure 5). The clinical feature of the positive reactions and its histology was compatible with prurigo, and the prurigoes often encountered with $\mathrm{AD}$ are well-known Prurigoes of Besnier. As this persistent multiple prurigoes of Besnier disappeared for years after HDMs were eliminated based on a mite fauna investigation, it is possible to consider that the $a$-acaridial usually present in Tps is the causation of Prurigo Besnier of $\mathrm{AD}$ [17]. Tps, however, appear in the new houses or new rooms first, and then they are gradually replaced by Dps and Dfs. Tarsonemus SPs are common HDMs along with dermatophagoides, however, as culture has not been successful with tarsonemus, the presence of a -acaridial in tarsonemus has been unknown. When $\alpha$-acaridial was newly discovered, the commercial distribution of it was proposed. Considering that $\alpha$-acaridial was also a primary sensitizer, the plan was abandoned, because its distribution for patch testing could newly cause $\mathrm{AD}$ on many subjects. The fact that Tp has such a primary and strong contact sensitizer should only be recognized.

\section{Evidence of causation (2): The presence of mite fauna in AD patients' homes and the effects of mite elimination on eczema}

At the time when the national research team for atopic diseases was formed in 1989, the authors joined to investigate mite allergy in $\mathrm{AD}$, and also to develop a new technical method to investigate mite fauna in the homes of the $\mathrm{AD}$ patients. The new method was requested to be much more simple and easy than the complicated classical acarological method [7]. We decided to make use of the many plastic culture plates (petri dish) for bacterial examination in the laboratory of the hospital. $4 \mathrm{ml}$ of agar was added with methylene blue at $0.01 \%$ and dissolved in a small hot water bath. The patients' homes were visited by a research staff who collected house dusts from 10 to 15 places, including sleeping mats, blankets, pillows, carpets, tatami (Japanese straw mats), teddy bears, sofas, chairs, closets, etc. A $320 \mathrm{~W}$ electric vacuum cleaner was operated with an automatic switch for 20 seconds. House dusts from 1 square meter measured by a 4 meter long circular string were exactly aspirated, and the weights were measured in the laboratory. $50 \mathrm{mgs}$ of

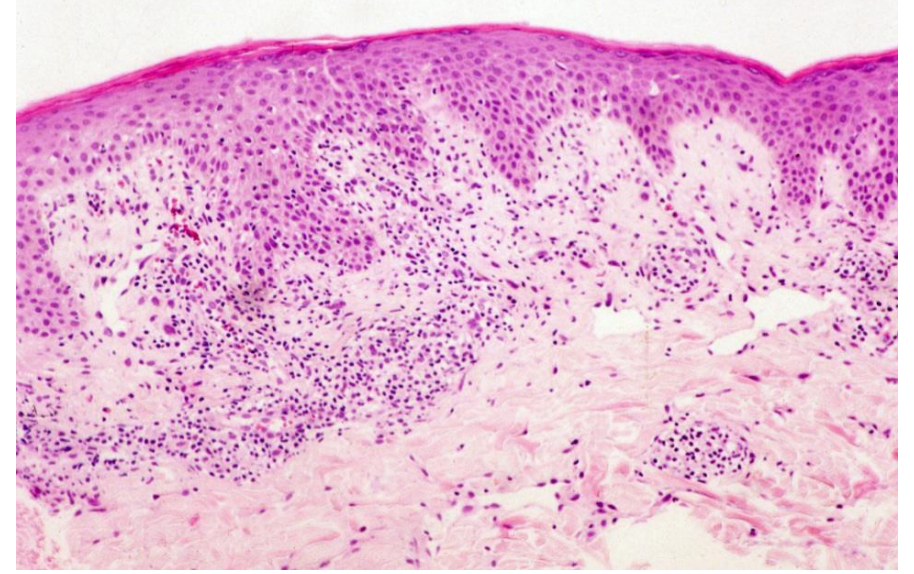

Figure 5. Histopathology of $\alpha$-acaridial-induced ( $0.3 \%$ in petrolatum) prurigo-like nodule examined on the 24 th day of a patch test on a female atopic dermatitis patient. Mild acanthosis and lymphocytic infiltration in the upper dermis are noted. These lymphocytes were mainly $\mathrm{CD} 4$ positive T-cells, indicating that this long term patch test positive reaction is also a product of contact allergy. 
Table 3. Patch test results of mite components [7].

\begin{tabular}{|c|c|c|c|c|c|c|c|c|c|}
\hline \multirow{2}{*}{\multicolumn{2}{|c|}{ Mite components Diseases }} & \multicolumn{4}{|c|}{ Atopic dermatitis } & \multicolumn{4}{|c|}{ Other dermatitis } \\
\hline & & \multicolumn{2}{|c|}{$(+),(2+)$} & \multirow{2}{*}{$\begin{array}{c}?(+),(-) \\
102\end{array}$} & \multirow{2}{*}{$\frac{\mathrm{n}}{190}$} & \multicolumn{2}{|c|}{$(+),(2+)$} & \multirow{2}{*}{$\frac{?(+),(-)}{72}$} & \multirow{2}{*}{$\frac{n}{201}$} \\
\hline 1 & Dermatophagoides mix ( $40 \%$ pet.) & 88 & $(46.3 \%)$ & & & 129 & $(64.2 \%)$ & & \\
\hline 2 & Geranial ( $5 \%$ pet.) & 22 & $(53.7 \%)$ & 19 & 41 & 28 & $(68.3 \%)$ & 13 & 41 \\
\hline 3 & Geraniol (5\% pet.) & 2 & $(4.9 \%)$ & 39 & 41 & 7 & $(17.1 \%)$ & 34 & 41 \\
\hline 4 & $\alpha$-Acaridial ( $0.3 \%$ pet. $)$ & 24 & $(35.8 \%)$ & 43 & 67 & 41 & $(57.7 \%)$ & 30 & 71 \\
\hline 5 & DHBA ( $1 \%$ cream $)$ & 3 & $(1.6 \%)$ & 187 & 190 & 3 & $(1.5) \%$ & 198 & 204 \\
\hline
\end{tabular}

DHBA: Dehydrobenzaldehyde

HDMs are one of common contact sensitizers in our daily life, therefore, sensitization to them are seen not only in AD but also in various other dermatitis group. However, AD cases in this table contain a type whose serum IgE is high, the RAST for HDMs are high and still patch test to HDMs is negative, which is not present in other dermatitis group.

the collected house dust were dissolved in the warmed liquid methylene blue agar (MBA), poured into the plastic plate and it was left cooled until it became solid. Then the plate was put under a microscope and the number of house dust mites (HDM) were counted along the lines on a transparent plate having parallel lines in order to avoid any double counts of the same mite (Figure 6). When there were $30 \mathrm{HDMs}$ on the plate and the weight of the house dust collected at that specific place was $500 \mathrm{mgs}$, the HDM present at the place was $300 / 1 \mathrm{~m} 2$. The method was titled as the Methylene-blue agar (MBA) method. The species could be identified from the outlook of the mites [18].

Firstly, mite fauna was investigated across all four seasons, according to the species of the interiors. The mite fauna investigated among 550 severe AD patients that were reported as a result of the national investigation is described in Tables 4 and 5. According to the results, $88.9 \%$ of the HDM were dermatophgoides, and the second species in number was the Tarsonemus group. This tendency was similar when investigated again in the recent 7 years (Table 5). RAST or patch tests with dermatophagoides were possible, however, as the trial to culture Tarsonemus failed twice, and RAST or patch test of this species has been impossible till today.

\section{What were the effects of eliminating HDM for severe, intractable, generalized $\mathrm{AD}$ patients?}

Mild cases of $\mathrm{AD}$ can easily be improved through just an antisymptomatic treatment. However, with severe, intractable cases of $\mathrm{AD}$, generalized eczema, lichenification of the face and flexor surfaces, dirty neck, bronchial asthma and Prurigo Besinier are difficult to be cured, as the recurrence of eczema is quite common.

When the crucial causes were accumulated by the results of patch tests, RAST, the production of Prurigo by $\alpha$-acaridial, and overwhelming percentage of dermatophagoides group in AD patients' homes (Table 5), it suggested that the eliminate of as much HDM as possible was essential for severe and intractable cases of AD. Such a kind of treatment to discover and eliminate causative allergens with intractable allergic diseases had been called "allergen control" and had successfully cured many cases of pigmented cosmetic dermatitis and pustulosis palmaris et plantaris in the 1980s $[19,20]$. In the third year of the national investigation of intractable $\mathrm{AD}$, double-blind tests to evaluate the effect of mite elimination were performed. The first trial of this investigation failed, when the odd number of six severe $A D$ patients who were clearly sensitized to HDM by RAST or patch tests were requested to perform mite fauna investigation, and mite rich furniture was removed and mite free mattresses were introduced. On the other hand, the even number of another six AD patients of the same grade of severity and hypersensitivity to HDM had anti-symptomatic treatment only, ignoring mite allergy. Two months later, none of the latter group of patients came back to the hospital, and when questioned over telephone, they revealed that their eczema did not improve by the same anti-symptomatic treatment which they had received similarly in their previous hospitals. Therefore, in the next trial, the methods of the double blind tests were changed. All 34 intractable AD patients who were hypersensitive to HDM were investigated with mite fauna of their homes. A year or two later, the mite fauna was again examined in the same seasons to eliminate seasonal variations of mite with all 34 patients, and the symptoms of eczema were evaluated. At the same time, the grade of environmental improvement was determined, whether or not it was conducted completely as had been previously requested, or incomplete so as to leave some interiors where mites proliferated, even though improvement was performed partially.

The consumed amount of corticosteroid ointments per month was recorded for the comparison of the two groups using the Wilcoxon test and the t-test. Tables 6 and 7 show the results of this second trial of the double blind test. 17 cases of $\mathrm{AD}$ which could attain complete or almost complete environmental improvement according to the results of mite fauna investigation (hereinafter referred to as the "complete group"), and other 17 cases which could not attain complete environmental improvement, leaving some mite-rich interiors (hereinafter referred to as the "incomplete group"), did not show any significant difference in their backgrounds before the trial was made, including age, serum IgE levels, average RAST, etc. (Table 5). Before this study was conducted, a national research team of $\mathrm{AD}$ came up with a four level grading system to determine the severity of eczema. This simple evaluation system graded conditions as being severe (3), moderate (2), mild (1) and mostly cured (0). Previously there had been various complicated scoring systems, but the new system was simplified due to the fact that the main goal among all patients was to be mostly cured (0) with no erythema, lichenification, itching or vesicles $[21,22]$. This four level grading system also shared a similarity with the previous systems as taking photographs of the same locations to determine the improvements. This new system was much more easier to adopt and the best thing about it was that the level of severity measured by different researches could now be unified. Table 6 had shown that when skin symptoms were compared, the marked improvement of severe $\mathrm{AD}$ was noted in $88 \%$ of the complete group, while it was only $35 \%$ of the incomplete group. The decrease of more than $70 \%$ of HDM was noted in $82 \%$ of the complete group, while it was $47 \%$ in the incomplete group. The decrease of mite in the first to fifth mite-abundant interior equipment was $70 \%$ in the complete group, while it was only $22 \%$ in the incomplete group. It meant that $78 \%$ of mites expected to worsen the allergic reactions still remained in the incomplete group.

The dosage of corticosteroid ointments needed in a month decreased from $67.9 \mathrm{~g}$ to $11.5 \mathrm{~g}$ on average in the complete group, while it was $68.2 \mathrm{~g}$ to $40.6 \mathrm{~g}$ in the incomplete group, and all of the above described differences were statistically significant. This investigation revealed the importance of mite allergy among $\mathrm{AD}$ patients either by IgE RAST or patch test and secondly, the importance of mite fauna in 
A. Dust collected by an electric vaccum cleaner using a paper filter bag

B. 1. Collected $0.05 \mathrm{~g}$

$$
+
$$

2. Add $0.1 \%$ neutral detergent

$$
+
$$

3. $0.01 \%$ Methylene blue

$$
\left.\begin{array}{l}
0.10 \% \text { Sodium lauryl sulfate (SLS) } \\
0.20 \% \text { Methylparaben } \\
1.50 \% \text { Agar }
\end{array}\right\} \begin{aligned}
& \text { MBA } 4 \mathrm{ml} \\
& \text { keep at } 60^{\circ} \mathrm{C}
\end{aligned}
$$

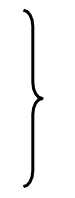

C. Dust mixed and suspended in heat dissolved MBA in a petri dish $(\phi 9 \mathrm{~cm})$ and kept at room temperature to become solid$$
\downarrow
$$

D. Count mites using a standard microscope

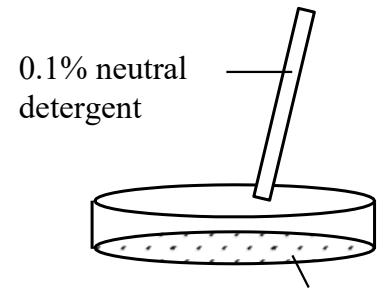

\begin{tabular}{|c|c|c|c|c|c|c|}
\hline \multirow{2}{*}{\multicolumn{2}{|c|}{$\begin{array}{lll} & \text { number of patients } \\
\text { interior } & \text { season } \\
\end{array}$}} & \multirow{2}{*}{$\begin{array}{c}\text { Spring } * 2 \\
134\end{array}$} & \multirow{2}{*}{$\begin{array}{c}\text { Summer *3 } \\
167\end{array}$} & \multirow{2}{*}{$\begin{array}{c}\text { Autumn *4 } \\
136\end{array}$} & \multirow{2}{*}{$\frac{\text { Winter } * 5}{113}$} & \multirow{2}{*}{$\begin{array}{c}\text { Total } * 6 \\
550\end{array}$} \\
\hline & & & & & & \\
\hline 1 & Carpet(including mat ) & $\begin{array}{l}120 \\
(262)\end{array}$ & $\begin{array}{c}352 \\
(282)\end{array}$ & $\begin{array}{l}279 \\
(226)\end{array}$ & $\begin{array}{l}113 \\
(217)\end{array}$ & $\begin{array}{c}221 \\
(987)\end{array}$ \\
\hline 2 & Tatami mat (Japanese straw mat) & $\begin{array}{c}39 \\
(143)\end{array}$ & $\begin{array}{c}87 \\
(178)\end{array}$ & $\begin{array}{c}57 \\
(148)\end{array}$ & $\begin{array}{c}44 \\
(112)\end{array}$ & $\begin{array}{c}59 \\
(581)\end{array}$ \\
\hline 3 & Flooring & $\begin{array}{c}11 \\
(121)\end{array}$ & $\begin{array}{c}27 \\
(201)\end{array}$ & $\begin{array}{c}25 \\
(151)\end{array}$ & $\begin{array}{c}13 \\
(131)\end{array}$ & $\begin{array}{c}20 \\
(604)\end{array}$ \\
\hline 4 & Mattress & $\begin{array}{c}19 \\
(257)\end{array}$ & $\begin{array}{c}56 \\
(253)\end{array}$ & $\begin{array}{c}104 \\
(239)\end{array}$ & $\begin{array}{c}32 \\
(211)\end{array}$ & $\begin{array}{c}53 \\
(960)\end{array}$ \\
\hline 5 & Blanket (including towelket) & $\begin{array}{c}21 \\
(116)\end{array}$ & $\begin{array}{c}59 \\
(154)\end{array}$ & $\begin{array}{c}119 \\
(131)\end{array}$ & $\begin{array}{c}24 \\
(127)\end{array}$ & $\begin{array}{c}57 \\
(528)\end{array}$ \\
\hline 6 & Floor under tatami mat & $\begin{array}{l}380 \\
(22)\end{array}$ & $\begin{array}{l}950 \\
(25)\end{array}$ & $\begin{array}{c}1,570 \\
(19)\end{array}$ & $\begin{array}{c}1,441 \\
(12)\end{array}$ & $\begin{array}{c}1,016 \\
(78)\end{array}$ \\
\hline 7 & Mattress of bed & $\begin{array}{c}79 \\
(124)\end{array}$ & $\begin{array}{c}129 \\
(154)\end{array}$ & $\begin{array}{c}181 \\
(113)\end{array}$ & $\begin{array}{c}57 \\
(109)\end{array}$ & $\begin{array}{c}112 \\
(500)\end{array}$ \\
\hline 8 & Pillow & $\begin{array}{c}5 \\
(71)\end{array}$ & $\begin{array}{c}13 \\
(90)\end{array}$ & $\begin{array}{c}19 \\
(75)\end{array}$ & $\begin{array}{c}5 \\
(61)\end{array}$ & $\begin{array}{c}11 \\
(297)\end{array}$ \\
\hline 9 & Japanese seat cushion & $\begin{array}{c}27 \\
(29)\end{array}$ & $\begin{array}{c}31 \\
(30)\end{array}$ & $\begin{array}{c}58 \\
(35)\end{array}$ & $\begin{array}{c}22 \\
(16)\end{array}$ & $\begin{array}{c}37 \\
(110)\end{array}$ \\
\hline 10 & Sofa & $\begin{array}{l}210 \\
(55)\end{array}$ & $\begin{array}{l}479 \\
(69)\end{array}$ & $\begin{array}{l}392 \\
(43)\end{array}$ & $\begin{array}{l}396 \\
(42)\end{array}$ & $\begin{array}{c}301 \\
(209)\end{array}$ \\
\hline 11 & Chair & $\begin{array}{c}77 \\
(59)\end{array}$ & $\begin{array}{l}325 \\
(89)\end{array}$ & $\begin{array}{l}658 \\
(74)\end{array}$ & $\begin{array}{l}332 \\
(50)\end{array}$ & $\begin{array}{c}363 \\
(272)\end{array}$ \\
\hline 12 & Mite-proof mattress & $\begin{array}{c}4 \\
(54)\end{array}$ & $\begin{array}{c}18 \\
(72)\end{array}$ & $\begin{array}{c}14 \\
(63)\end{array}$ & $\begin{array}{c}5 \\
(48)\end{array}$ & $\begin{array}{c}11 \\
(237)\end{array}$ \\
\hline 13 & Mite-proof tatami & $\begin{array}{c}5 \\
(8)\end{array}$ & $\begin{array}{l}12 \\
(8)\end{array}$ & $\begin{array}{l}50 \\
(9)\end{array}$ & $\begin{array}{c}4 \\
(6)\end{array}$ & $\begin{array}{c}20 \\
(31)\end{array}$ \\
\hline 14 & Mite-proof pillow & $\begin{array}{c}1 \\
(12)\end{array}$ & $\begin{array}{c}2 \\
(12)\end{array}$ & $\begin{array}{c}3 \\
(10)\end{array}$ & $\begin{array}{c}2 \\
(8)\end{array}$ & $\begin{array}{c}2 \\
(42)\end{array}$ \\
\hline 15 & $\begin{array}{c}\text { Others } \\
\text { (ex. Drawer, Closet, etc.) }\end{array}$ & $\begin{array}{c}121 \\
(179)\end{array}$ & $\begin{array}{c}136 \\
(254)\end{array}$ & $\begin{array}{l}321 \\
(207)\end{array}$ & $\begin{array}{c}85 \\
(157)\end{array}$ & $\begin{array}{c}171 \\
(797)\end{array}$ \\
\hline
\end{tabular}

collected dust $0.05 \mathrm{~g}$

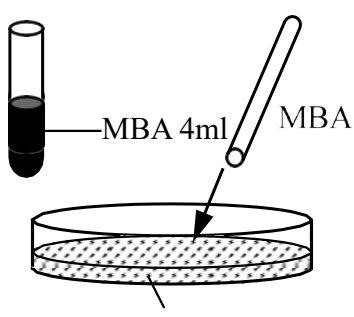

depth $2 \mathrm{~mm}$

Figure 6. Mite separation from house dust through Methylene Blue Agar (MBA)

Table 4. Average numbers of mites of various interiors in the homes of 550 severe atopic dermatitis patients studied in five years (MBA Mite Research Laboratory) [7]. (Total number of mites $* 1 / 1 \mathrm{~m}^{2} / 20 \mathrm{sec}$ aspiration, by a vacuum cleaner at $320 \mathrm{~W}$ )

*1 Counted by the MBA method, except for insects, in which we regarded the egg and mite shell were counted as one.

The figure in ( ) is number of sample.

*2 March - May

*3 June - August

*4 September - November

*5 December - February

*6 January - December 
Table 5. Mite fauna in house dusts collected from the houses of atopic dermatitis patients in Japan (2008-2014).

Number of AD patients: 117

Number of house dust samples: 2,072

\begin{tabular}{|c|c|c|c|c|c|}
\hline ACARINA & Families & Total & Mean & STV & $\%$ \\
\hline \multirow[t]{4}{*}{ Astigmata } & Pyroglyphidae & $686,784.1$ & 331.46 & $1,777.33$ & 92.94 \\
\hline & Acaridae & $1,390.6$ & 0.67 & 5.20 & 0.19 \\
\hline & Glycyphagidae & $4,737.6$ & 2.29 & 46.31 & 0.64 \\
\hline & Others & 871.7 & 0.42 & 4.05 & 0.12 \\
\hline \multirow[t]{12}{*}{ Prostigmata } & Tarsonemidae & $26,762.6$ & 12.92 & 160.89 & 3.62 \\
\hline & Scutacaridae & 1.0 & 0.00 & 0.02 & 0.00 \\
\hline & Cheyletidae & $6,320.7$ & 3.05 & 17.51 & 0.86 \\
\hline & *Chelacaropsis & 81.6 & 0.04 & 0.63 & 0.01 \\
\hline & Tetranychidae & 46.9 & 0.02 & 0.48 & 0.01 \\
\hline & Taenuipalpidae & 68.9 & 0.03 & 0.43 & 0.01 \\
\hline & Bdellidae & 78.1 & 0.04 & 0.91 & 0.01 \\
\hline & Cunaxidae & 66.5 & 0.03 & 0.73 & 0.01 \\
\hline & Tydeide & 1.0 & 0.00 & 0.02 & 0.00 \\
\hline & Raphignathidae & 68.1 & 0.03 & 0.57 & 0.01 \\
\hline & Erythraeudae & 1.0 & 0.00 & 0.02 & 0.00 \\
\hline & Eriophyidae & 1.0 & 0.00 & 0.02 & 0.00 \\
\hline Mesostigmata & & $5,103.2$ & 2.45 & 26.50 & 0.69 \\
\hline Cryptostigmata & & $5,594.2$ & 2.70 & 32.09 & 0.76 \\
\hline Unknown & & 943.4 & 0.46 & 3.95 & 0.13 \\
\hline Total & & $738,918.1$ & 356.62 & $1,797.55$ & 100.00 \\
\hline Total mites $/ \mathrm{m}^{2}$ & & $931,878.3$ & 449.70 & $2,057.40$ & \\
\hline Total mites $/ \mathrm{m}^{2}(\log )$ & & $3,678.7$ & 1.80 & 0.90 & \\
\hline Total mites/g & & $3,646,790.1$ & $1,760.00$ & $4,899.80$ & \\
\hline Total mites/g(log) & & $5,501.1$ & 2.70 & 0.90 & \\
\hline
\end{tabular}

Table 6. Conditions of $34 \mathrm{AD}$ patients (in table 7) who were incurable [23]

\begin{tabular}{|c|c|c|c|}
\hline & & \multicolumn{2}{|l|}{ Mite elimination from the patients' homes } \\
\hline & & Almost complete & Incomplete \\
\hline 1. & Number of patients & 17 (males 10, females 7) & 17 (males 11, females 6) \\
\hline 2. & Average age & 19.5 (range : 2 to 29 ) & 23.4 (range : 12 to 59 \\
\hline 3. & Average serum IgE (IU/ml) & 5,037 (range : 70 to 22,100 ) & 7,904 (range : 173 to 20,030 ) \\
\hline 4. & $\begin{array}{l}\text { Average RAST } \\
\text { UA to house dust mite }\end{array}$ & $\begin{array}{l}146.0 \\
80.5 \\
\text { (more than } 17.5 \text { in } 5 \text { cases among } 17 \text { ) }\end{array}$ & $\begin{array}{l}195.0 \\
\text { (more than } 17.5 \text { in } 3 \text { cases among } 17) \\
148.3 \\
\text { (more than } 17.5 \text { in } 5 \text { cases among } 17 \text { ) }\end{array}$ \\
\hline 5. & $\begin{array}{l}\text { Percentage of } \\
\text { mite RAST }>10 \mathrm{UA}\end{array}$ & $14 / 17=82.4 \%$ & $13 / 17=76.5 \%$ \\
\hline 6. & $\begin{array}{l}\text { Number of patients who showed more than } 10 \text { UA for } \\
\text { each allergen except for mites and house dust }\end{array}$ & $\begin{array}{l}\text { Japanese cedar: 4, Candida and mold: } 1 \text {, } \\
\text { Japanese nutmeg, Mugwort: } 2 \text {, } \\
\text { Egg white: } 3 \text {, } \\
\text { Wheat: } 1 \text {, Rice: } 1 \text {, Milk: } 1 \text {, Soybeans: } 1 \text { (in same } \\
\text { patient) }\end{array}$ & $\begin{array}{l}\text { Japanese cedar: 2, Candida and mold: 3, Japanese nutmeg: } 2 \text {, } \\
\text { Mugwort: 2, } \\
\text { Cat dander: } 1\end{array}$ \\
\hline 7. & $\begin{array}{l}\text { Rate of positive patch tests to three crushed live mites } \\
\text { (More than } \\
\text { (+) by ICDRG standards) }\end{array}$ & $9 / 12=75 \%$ & $6 / 14=42.9 \%$ \\
\hline 8. & $\begin{array}{l}\text { Number of patients who showed hypersensitivity to } \\
\text { metals by } \\
\text { a patch test (More than }(+) \text { by ICDRG standards) }\end{array}$ & $\mathrm{Ni}, \mathrm{Co}: 9, \mathrm{Hg}: 2, \mathrm{Cr}: 2, \mathrm{Sn}: 1$, others: 2 & Ni, Co: 4, Hg 5, Cr: 4, Sn: 3, others: 2 \\
\hline
\end{tabular}

the $\mathrm{AD}$ patient's homes, in order to precisely eliminate the presence of real allergens present in their home environment. Thirdly, what $\mathrm{AD}$ patients desired the most was the remarkable improvement of generalized skin symptoms with severe eczema with incessant itching, and such hope could be attained through the sufficient elimination of HDMs. Insufficient elimination of HDM among the incomplete group mostly failed to obtain remarkable improvements. The presence of statistical significance in several aspects between the complete and incomplete groups was an excellent evidence that HDM allergy is in fact the most important causation of $\mathrm{AD}$, and even though when $\mathrm{AD}$ is severe and intractable, the investigation of mite allergy and mite fauna, accompanied by environmental improvement to sufficiently decrease HDM to less than $50 / \mathrm{m} 2 / 20$ seconds aspiration is most recommended [23].

One year later, Tan et al reported a double blind test using the investigation on the environmental mite antigens, accompanied by environmental improvement. The results were similar to the previously described report [24], and there were impressive cases whose eczema improved remarkably. Since the 21 st century, the discovery of $a$-acaridial to produce prurigoes for more than 3 weeks up to 6 months suggested that the well-known Prurigo Besnier is also caused by HDM, especially Tps. Up to 2016, severe and intractable 85 AD and Prurigo 
Table 7. The changes of mite fauna and skin symptoms brought about by environmental improvement of the homes of 34 AD patients in table 6 [23].

\begin{tabular}{|c|c|c|}
\hline Environmental improvement (Mite elimination) & Almost complete & Incomplete \\
\hline Number of AD patients & 17 & 17 \\
\hline More than $70 \%$ decrease in the original mite fauna & $\begin{array}{c}14(82 \%) \\
{[a]}\end{array}$ & $\begin{array}{c}8(47 \%) \\
{[\mathrm{b}]}\end{array}$ \\
\hline Decrease in mite fauna among the first to fifth mite abundant interior equipments & $70 \%$ & $22 \%$ \\
\hline $\begin{array}{l}\text { Symptoms of atopic dermatitis } \\
\left\{\begin{array}{l}\text { Remarkably improved } \\
\text { Improved } \\
\text { No change }\end{array}\right. \\
\text { ( ) indicates the rate of improvement }\end{array}$ & $\begin{array}{lll}\begin{array}{l}9 \\
6\end{array} & 15(88 \%) \\
2 & & \\
& & {[\mathrm{c}]}\end{array}$ & $\begin{array}{lll}2 & \\
4 & 6(35 \%) \\
11 & \\
& {[\mathrm{~d}]}\end{array}$ \\
\hline 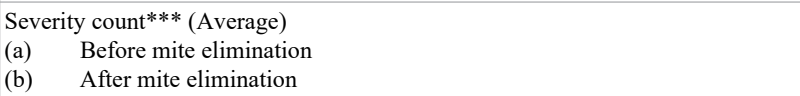 & $\begin{array}{l}2.7 \\
0.7\end{array}$ & $\begin{array}{l}2.8 \\
1.7\end{array}$ \\
\hline $\begin{array}{l}\text { Average dosage of corticosteroid ointments given in a month (mean } \pm \text { SD) } \\
\text { (a) When mite elimination began } \\
\text { (b) After mite elimination }\end{array}$ & $\begin{array}{l}67.9 \pm 30.5 \mathrm{~g} \\
{[\mathrm{e}]} \\
11.5 \pm 12.5 \mathrm{~g} \\
{[\mathrm{f}]}\end{array}$ & $\begin{array}{l}68.2 \pm 30.1 \mathrm{~g} \\
\quad[\mathrm{~g}] \\
40.6 \pm 17.3 \mathrm{~g} \\
\quad[\mathrm{~h}]\end{array}$ \\
\hline
\end{tabular}

*** Severity count of dermatitis, (3: Severe, 2: Moderate, 1: Mild, 0: Mostly cured)

\begin{tabular}{|c|c|c|c|}
\hline \multicolumn{1}{|c|}{ Wilcoxon's method } & \multicolumn{2}{c}{ Statistical evaluation } \\
\hline Subjects & Z & 0.0012 \\
\hline $\mathrm{c} \& \mathrm{~d}$ & -3.2392 & 0.0010 \\
\hline $\mathrm{e} \& \mathrm{f}$ & -3.2990 & near 0 & $*$ \\
\hline $\mathrm{f} \& \mathrm{~h}$ & -4.2537 & 0.0219 & $*$ \\
\hline $\mathrm{g} \& \mathrm{~h}$ & -2.2917 & 0.5682 \\
\hline $\mathrm{e} \& \mathrm{~g}$ & 0.5706 & $*$ \\
\hline
\end{tabular}

$* * \mathrm{p}<0.01 * \mathrm{p}<0.05$

t-test

$\mathrm{a} \& \mathrm{~b} \mathrm{p}<0.05$

Table 8. The effect of mite elimination based on the investigated mite fauna of each severe and intractable AD patients' home since the year 2006 to 2015 Number of severe and intractable AD patients: 85 (57 males and 28 females).

\begin{tabular}{|c|c|c|c|c|c|}
\hline & & \multicolumn{2}{|c|}{ Mean } & \multicolumn{2}{|c|}{ SD } \\
\hline \multicolumn{2}{|c|}{ Ages } & \multicolumn{2}{|c|}{30.0} & \multicolumn{2}{|c|}{14.0} \\
\hline \multicolumn{2}{|c|}{ Serum IgE } & $7,449.2$ & $\mathrm{IU} / \mathrm{ml}$ & $10,517.4$ & $\mathrm{IU} / \mathrm{ml}$ \\
\hline \multirow{2}{*}{ RAST } & $\mathrm{Dp}$ & 478.0 & UA & 670.3 & UA \\
\hline & Df & 523.9 & UA & 794.3 & UA \\
\hline \multicolumn{2}{|c|}{ Effect } & \multicolumn{2}{|c|}{ Number } & \multicolumn{2}{|c|}{ Percentage $(\%)$} \\
\hline \multicolumn{2}{|c|}{ Remarkable or moderate improvement } & \multicolumn{2}{|c|}{60} & \multicolumn{2}{|c|}{70.6} \\
\hline \multicolumn{2}{|c|}{ None or slight improvement } & \multicolumn{2}{|c|}{25} & \multicolumn{2}{|c|}{29.4} \\
\hline
\end{tabular}

Period of improvement followed up:

mean 15.7 months

SD 12.6 months

range $3-53$ months

Besnier cases have been investigated with HDM allergy either by IgE RAST and / or a patch test, followed by environmental improvement based on the mite fauna investigation of each AD patient's home. The production of mite-free mats for bedrooms has been ongoing since the late 1980s, and the rental rooms once covered by thick carpets or straw mats (Tatami) are gradually being replaced with simple flooring. The invention of high density cloth into which HDMs were impossible to penetrate through, made it easier for the patients to stay for 7 hours at night in mite-free conditions instead of the mite-rich mats in which they slept in previously.

The severe and intractable $\mathrm{AD}$ cases which had been followed up in the past 10 years and the results of mite elimination after the mite fauna investigation of their homes are shown in Table 8. This type of treatment has been successful at the rate of $70.6 \%$ for these patients when the advised environmental improvement was surely executed. The historical cases of such allergen control since 1979 are demonstrated from Figures 7 to 12.

\section{Discussion}

The term "Allergen control" was named for the treatments of such chronic allergic diseases in 1974, as well as various diseases including pigmented cosmetic dermatitis (the allergens were fragrances and pigments), pustulosis palmaris et plantaris (the allergens were streptococcus pyogenes in the tonsils at $80 \%$ and dental metals at $60 \%$ ), a part of SLE (the allergens were yellow pigments, Yellow No.11 \& No.10, in lipsticks and foundations), oral lichen planus (the allergens were mainly dental metals, metals from pans and rarely spices), and recently severe cases of alopecia areata (the allergens were dental metals, metals from pans and / or HDMs) [25].

When $\mathrm{AD}$ is intractable, recurrent and very much harassing due to severe and incessant itching, it should be cured to an almost normal skin condition free from itching. Simply just one or two pieces of evidence are not enough to fully understand the real causation and be able to reliable treatment. When evidence is accumulated, however, 


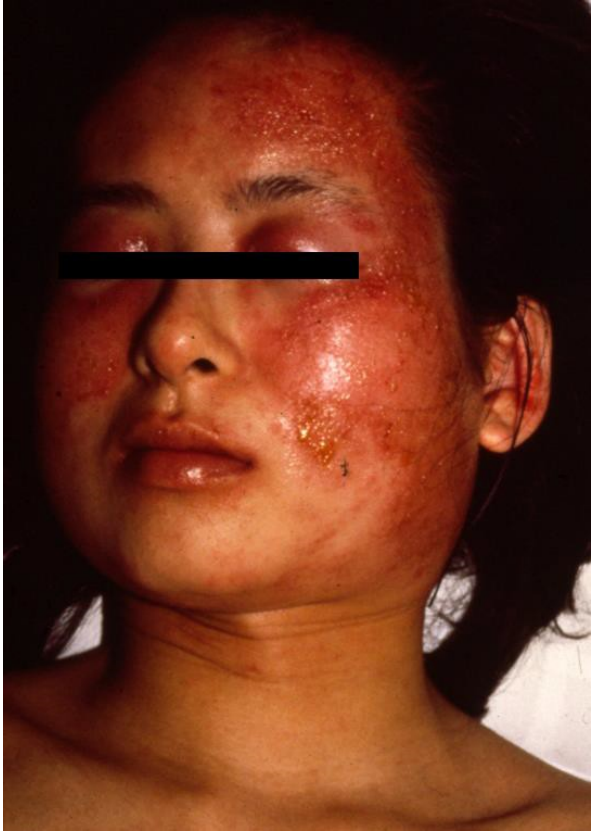

$7 \mathrm{a}$
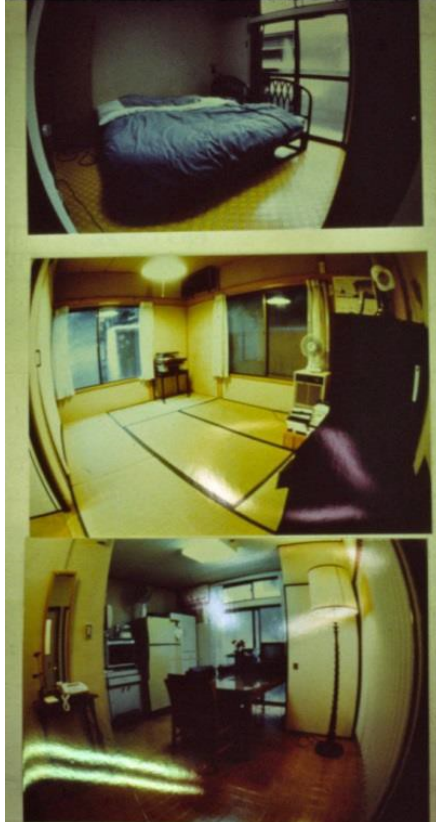

$7 \mathrm{~b}$

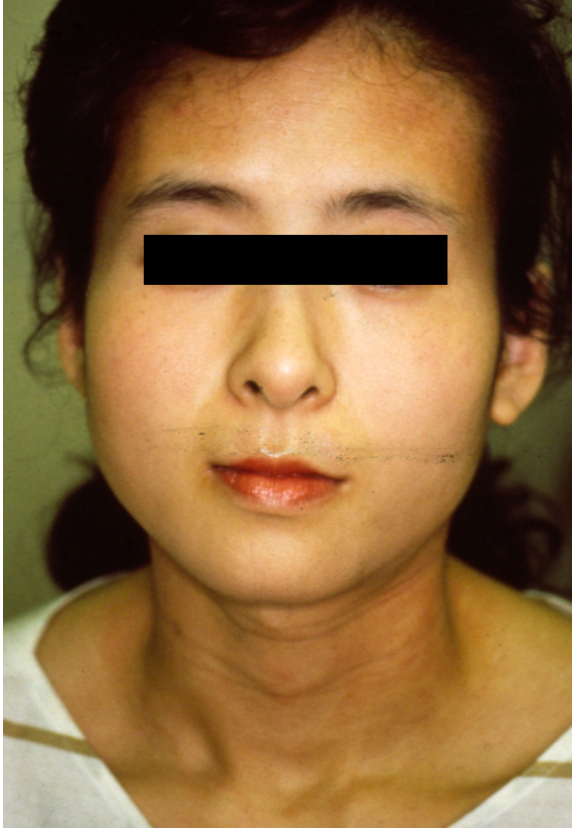

$7 \mathrm{c}$

Figure 7. A 31-year-old woman repeated severe relapse of atopic dermatitis (AD) three times in every May, which needed treatment by admission. Just after discharge, severe relapse happened again (7a). Serum IgE was over 3,000 IU/ml, RAST values for Dp and Df were high, and a patch test using three live mites was positive on the third day. Considering the severe relapse at home and improvement by admission, the treatment to stop the severe relapse was introduced by an investigation of mite fauna and then mite-rich interiors were removed. Mite-free mattresses were introduced and two mite rich carpets and Tatami mats were removed to attain flooring of the house. Fig. 7b shows the intermediate process of this mite elimination. After an environmental improvement was completed, the AD almost disappeared, and in May of the next year there was no more symptom of AD (7c) and severe relapse has never happened in the following 20 years. This was the world's first case whose severe relapse of AD has been blocked for many years by environmental improvement based on mite fauna investigation [26].

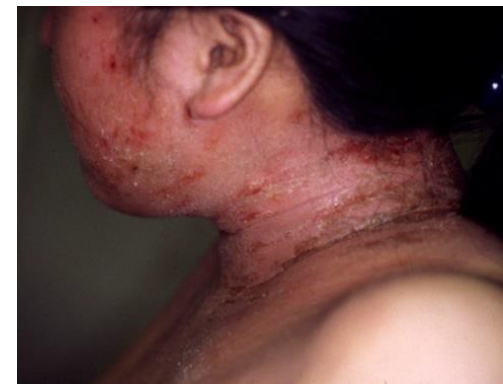

$8 \mathrm{a}$

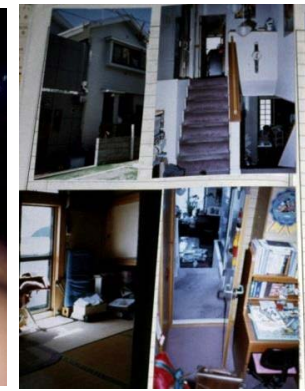

$8 \mathrm{~b}$

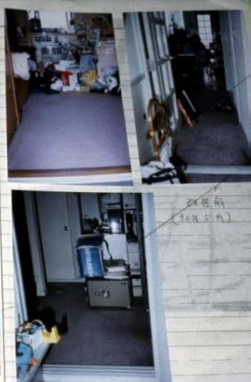

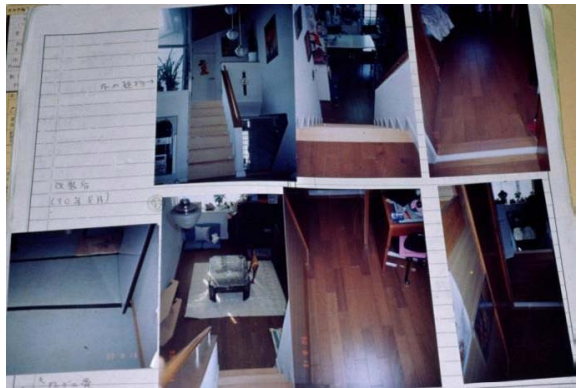

$8 \mathrm{c}$

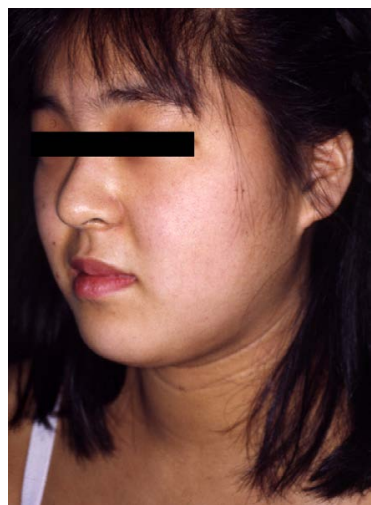

$8 \mathrm{~d}$

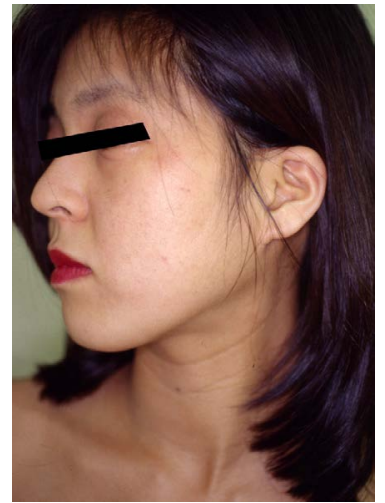

$8 \mathrm{e}$

Figure 8. A 20-year-old woman had suffered from AD of her entire body since childhood. It worsened so much in May that she was admitted to the hospital and treated. Soon after discharge, severe relapse again seized her (8a), therefore, her father requested for a stop to such relapses. Her home was all covered by thick carpets ( $8 \mathrm{~b}$ ), and on examination of mite fauna, abundant HDMs were counted, to which she was hypersensitive. All carpets and Tatami were removed to be replaced by flooring. Mite-free mattresses were introduced (8c). Through this improvement, her $\mathrm{AD}$ has been cured. 3 months after the first slide, there was no eczema at all (8d), and this cured condition continued for the following 6 years (8e) [9]. 


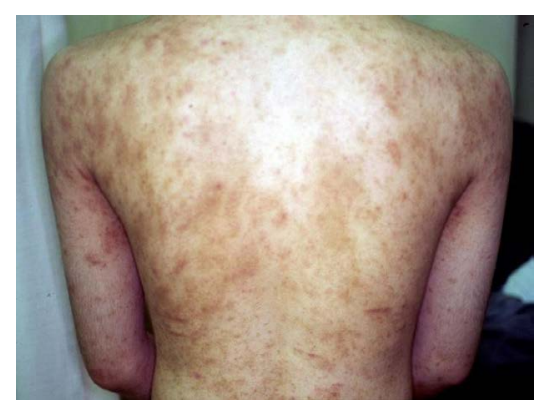

$9 \mathrm{a}$

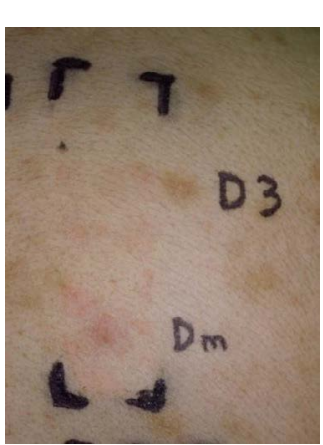

$9 \mathrm{c}$

$9 \mathrm{~b}$

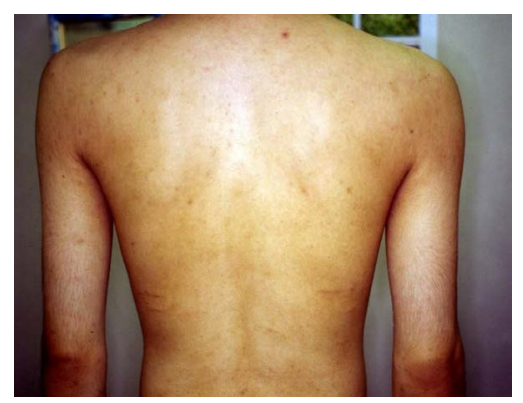

$9 \mathrm{~d}$

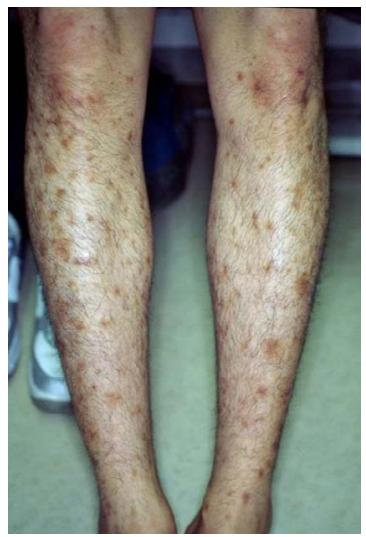

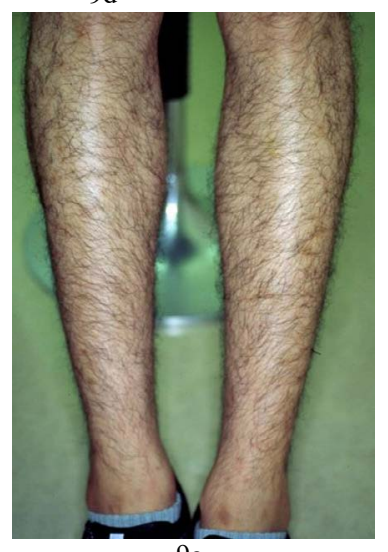

$9 \mathrm{e}$

Figure 9. A 19-year-old man had suffered from prurigo and eczema of his entire body from 3 years previously ( $9 a$ and $9 b$ ). He could not have been cured by the continual application of corticosteroid ointments and perorally administered antihistamines. Itching was severe. His serum IgE level was 1558 IU/ml, and RAST was positive to Dp at $88 \mathrm{UA}$, Df at $75 \mathrm{UA} / \mathrm{ml}$. A patch test showed $(2+)$ positive reaction to dermatophagoides mix on the third day $(9 \mathrm{c})$ with negative to 35 other common sensitizers showing that the main sensitizer was house dust mites. Mite fauna of his home revealed the presence of house dust mites in his mattresses, mats, chairs and a cleaner bag at 55 to $692 / \mathrm{m}^{2} / 20$ seconds aspiration. An environmental improvement was made to decrease the mite numbers to less than 20 dramatically improved his severe prurigo and eczema 8 month later, and the improvement has been maintained for the following two years $(9 \mathrm{~d}, 9 \mathrm{e})$, during which medication has been almost unnecessary [10].

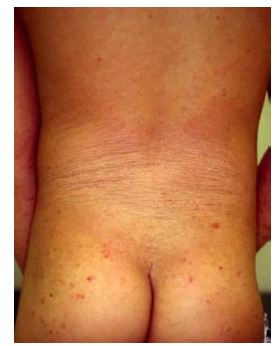

$10 \mathrm{a}$

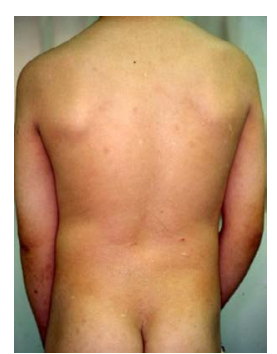

$10 \mathrm{e}$

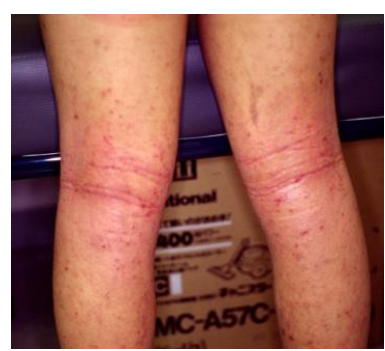

$10 \mathrm{~b}$

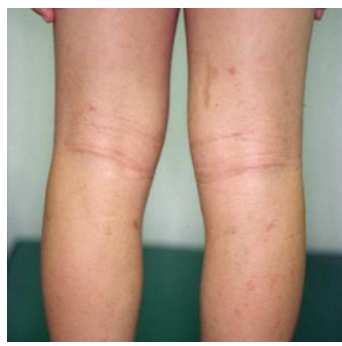

$10 \mathrm{f}$

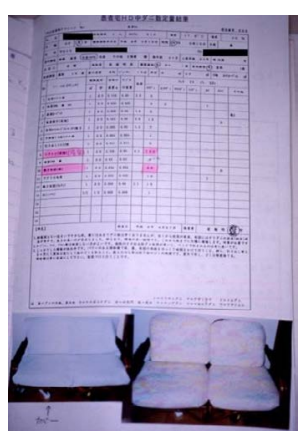

$10 \mathrm{~d}$

Figure 10. This 9-year-old boy had suffered from AD since 2 years of age. Eczema had been widespread and itching was severe (10a, 10b). Serum IgE level was at 5,200 IU/ml, with RAST values of Dp 70 UA and Df 665 UA, cedar pollen 13 UA, egg white 2 UA respectively, all other 8 allergens were 0 UA. As mite allergy was strong, the mite fauna was investigated in his home $(10 \mathrm{c}, 10 \mathrm{~d})$, and a mite-rich mat was replaced with a mite-free mat, and mite rich chair and sofa were repaired by changing the inner fibers and introducing flat surface artificial leather skin. After mite rich interiors were all replaced his eczema quickly disappeared, and two months later, clear normal skin was regained (10e, 10f). There has been no relapse of AD, when he was followed up for a year [28]. 


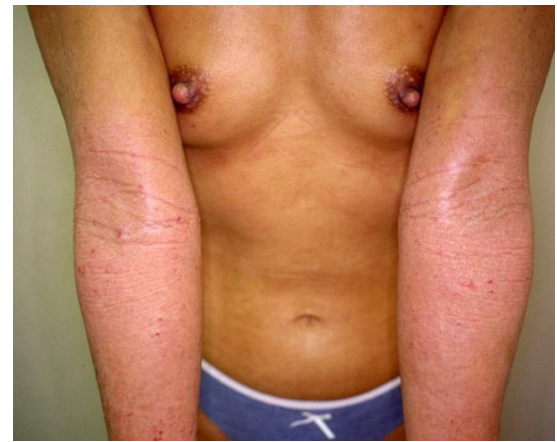

$11 \mathrm{a}$

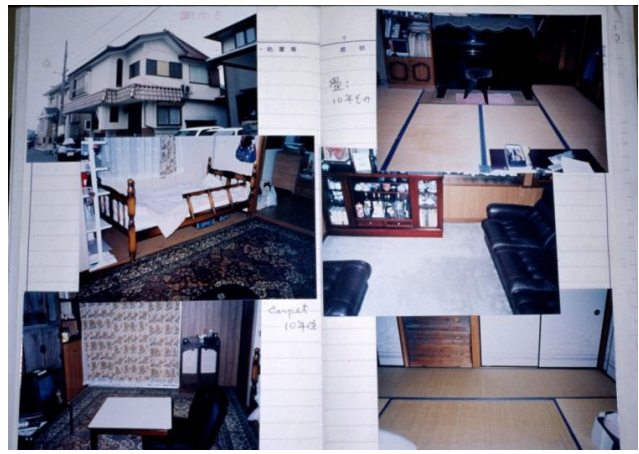

$11 \mathrm{~b}$

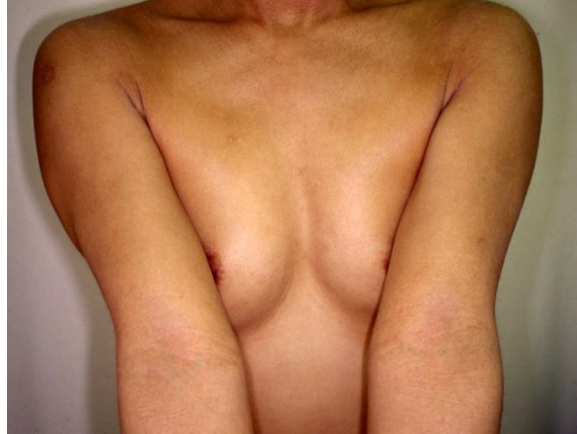

$11 \mathrm{~d}$

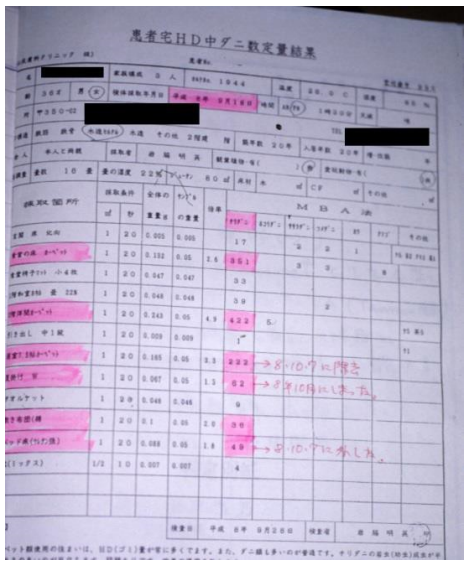

$11 \mathrm{c}$

Figure 11. This 36-year-old woman had suffered from severe itchy eczema of AD especially on the flexor surfaces of the extremities for several years (11a). Corticosteroid ointments applied daily did not improve this condition. As HDM allergy was remarkable, mite fauna of her house was investigated (11b). Abundant mite was found in 6 interiors indicated by pink ink in the mite fauna (11c). Introduction of mite-free mattresses, removal of mite rich carpets and other things produced remarkable improvement of her AD. 11d shows her cubital surface 3 months after this environmental improvement. She was followed up for one year without any relapse of AD [28].

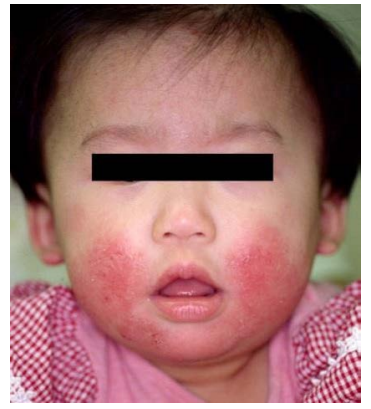

$12 \mathrm{a}$

$12 \mathrm{~d}$

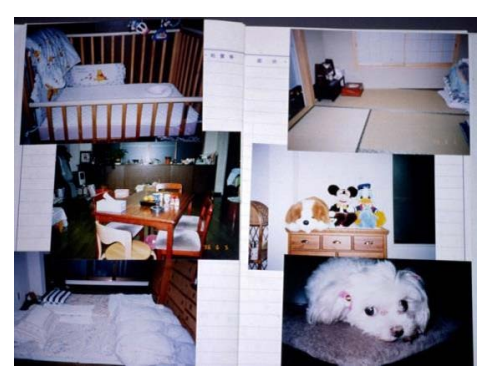

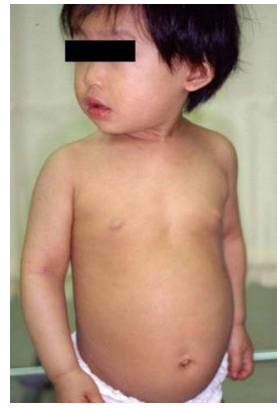

$12 \mathrm{~g}$

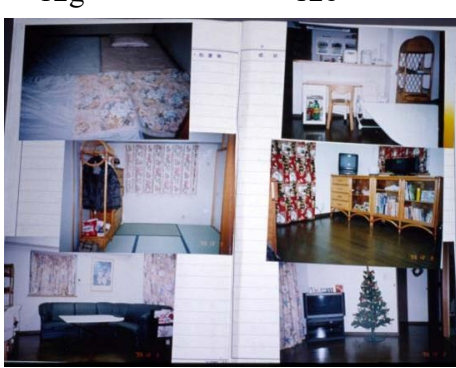

$12 \mathrm{f}$

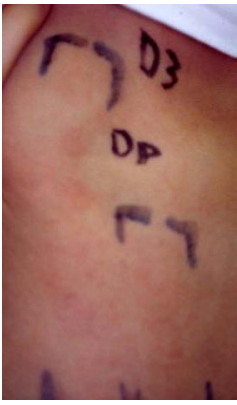

$12 \mathrm{~b}$
Figure 12. An 8-months-year old female baby started to suffer from severe erythema and papulo-vesicular eruption with incessant itching (12a). Daily application of strong class corticosteroid ointments did not improve the eczema, as it reoccurred every day. A patch test revealed that she was definitely sensitized to HDM, as is demonstrated with positive reactions to crushed Dps on day $3(12 \mathrm{~b})$ and day 7 (12c), indicating that she had delayed type hypersensitivity at this very early stage of life. From the carpet and mat on which she had crawled every day (12d), abundant HDMs were counted, indicated by pink ink on the mite fauna report (12e). As anti-symptomatic treatment did not work, all these mite rich interiors were replaced by mite-free mats, flooring, and mite resistant Tatami (12f). The results were excellent, since her eczema disappeared and never came back during one and a half year of follow up (12g). 
from the past information on the peculiar increase in serum IgE levels, RAST values of specific IgE which react to HDM at high percentages, clear and positive closed patch test reactions to only three live mites, strong and long term prurigo-like patch test reactions to $\alpha$-acaridial, mite fauna of the patients' homes of AD that $88.9 \%-92.9 \%$ of HDM are of the dermatophagoides family to which $70 \%$ to $80 \%$ of $\mathrm{AD}$ patients are hypersensitive, and finally, severe eczema, that seemed to continue endlessly had disappeared and the severe relapse ended for many months or years, and such results were reproducible in the 20 century and into the new millennium, it is safe to conclude that the main causation of severe and intractable AD is HDM allergy, and the most reliable treatment is to find out the mite allergy, followed by the investigation of mite fauna in the patients' homes to result in the precise elimination of HDM to less than $50 / \mathrm{m} 2 / 20$ senconds aspiration by an electric cleaner $[26,27,28]$.

In our experience, there are several barriers for this treatment. Firstly, it is easy to investigate serum IgE levels, RAST for HDMs, and when they are negative, perform a patch test of the Dermatophagoides mix (Chemothechnique, Sweden). Secondly, the photographs of the interior of the patients' home including all the rooms are taken, developed and recorded in the patients' medical record. These first and second processes to overcome AD are easy. However, when their symptoms are persistent and recurrent showing that anti-symptomatic treatments did not work, the mite fauna should be investigated, for then the doctors and patients can recognize how many HDMs are actually present in their contact environment. For that purpose, in Tokyo there has always been one institute that visits the patients' homes, investigates mite fauna and sends the results in two weeks to the clinic at the cost of approximately 412 US dollars. This third barrier can be overcome when such a laboratory becomes available in countries where many recurrent and intractable $\mathrm{AD}$ patients are actually present and continually suffering from $\mathrm{AD}$, with no positive effects of anti-symptomatic treatment. Fourthly, mite-free mattresses and bedding that use high density textile that mites cannot intrude should be produced and be available for people to conduct environmental improvement. It should be noted that floor heating should be suggested for patients living in countries with low temperatures so that they can remove carpets that are full of HDMs. We are living in a new age and such scientific allergen control of HDM is essential to cure patients suffering from severe and intractable $\mathrm{AD}$. There are rare exceptions of $\mathrm{AD}$ caused by the allergy to metals (Pseudo-atopic dermatitis, Shanon [29]) and to the malassezia group fungi, however, we should recognize that most common and important causation of AD is HDMs which live with us silently.

Lastly, when the AD patients do not perform the environmental improvement, indicated by mite fauna investigation, apparently the chance of improvement of $\mathrm{AD}$ decreases. In our experience, after the clear evidence of mite allergy by IgE RAST and or patch test is given, the demonstration of previous severe $\mathrm{AD}$ patients cured by mite elimination by color photographs has been an excellent material for persuasion. Showing the Figures 7 to 12 in this article is believed to be useful for $\mathrm{AD}$ patients in making the decision to conduct environment improvement. That is why we have included a number of color photographs in this article.

\section{Conclusion}

Atopic dermatitis is a common dermatological disease among many countries. When it is severe and persistent, we must recognize that HDM allergy is the cause and perform proper treatment through improving the living conditions of the $\mathrm{AD}$ patients. $\mathrm{AD}$ is not an incurable disease and those who treat $\mathrm{AD}$ must acknowledge the actual role of HDMs have towards this disease and also know the correct method to eliminate HDMs so that the patients can once again live life in a normal skin condition.

\section{References}

1. Palmer CAN, Irvine AD, Terron-Kwaiatkowski A (2006) Common loss-of-function variants of the epidermal barrier protein fillagrin are major predisposing factor for atopic dermatitis Nat Genet 38: 441-446. [Crossref]

2. Voorhorst R, Spieksma FTM, Varekamp H (1969) House-dust atopy and the housedust mite, Stafleu's Scientific Pub Co, Leiden 7-119.

3. Ishizaka K, Ishizaka T (1970) Biological function of gamma $E$ antibodies and mechanisms of reaginic hypersensitivity Clin Exp Immunol 6: 25-42. [Crossref]

4. Gunnar S, Johansson O, Juhlin L (1970) Immunoglobulin E in "healed" atopic dermatitis and after treatment with corticosteroids and azathioprine. Br J Dermatol 82 10-13. [Crossref]

5. Okudaira H, Hongo O, Ogita T, Haida M, Yamauchi N, et al. (1983) Serum IgE and IgE antibody levels in patients with bronchial asthma, atopic dermatitis, eosinophilic granulomas of the soft tissue (Kimura's disease) and other diseases. Ann Allergy 50: 51-54. [Crossref]

6. Okudaira H, Dohi M, Sugiyama H, Suko M, Miyamoto T, et al. (1989) Comparison of total IgE and anti-mite IgE antibody levels in the sera of patients with atopic dermatitis and/or atopic bronchial asthma Jpn J Allergol 38: 296-298. [Crossref]

7. Nakayama H, Kumei A (2003) House dust mite-an important causation of atopic dermatitis., SP World 31: 13-29

8. Rawle FC, Mitchell EB, Platts-Mills TA (1984) T cell responses to the major allergen from the house dust mite Dermatophagoides pteronyssinus, Antigen P1: comparison of patients with asthma, atopic dermatitis, and perennial rhinitis. J Immunol 133: 195-201. [Crossref]

9. Guin JD (1995) Chapter 46-The role of the house dust mite in atopic eczema (Eds.,) Nakayama H Practical Contact Dermatitis, McGraw Hill, NY 623-630

10. Nakayama H, Kumei A (2008) Importance of Mite Allergy in Atopic Dermatitis. Skin Research 7: Supple 10: 16-23

11. Bruynzeel Koomen C, Wichen DF, Toonstra J, Berrens L, Bruynzeel PL (1986) The presence of IgE molecules on epidermal Langerhans cells in patients with atopic dermatitis. Arch Dermatol Res 278: 199-205. [Crossref]

12. Novak N, Bieber T, Kraft S (2004) Immunoglobulin E-bearing antigen-presenting cells in atopic dermatitis Curr Allergy Asthma Rep 4: 263-269. [Crossref]

13. Seidenari S, Manzini BM, Danese P (1992) Positive patch tests to whole mite culture and purified mite extracts in patients with atopic dermatitis, asthma, and rhinitis. Ann Allergy 69: 201-206. [Crossref]

14. Sakurai M, Nakayama H, Kumei A (1991) Results of patch test with mite components in atopic dermatitis Am J Contact Dermatitis 2: 222-230. [Crossref]

15. Cardé RT, Miller JG (2004) Chemical ecology of astigmatoid mites (Eds.,) Kuwahara Y Advances in Insect Chemical Ecology, London. Pp: 76-109

16. Kuwahara Y (1997) Volatile compounds produced by two species of Dermatophagoides mites. Skin Research 39: 52-55.

17. Nakayama H, Kumei A, Kuwahara Y (2014) Atopic prurigoes produced by patch test The Allergy in Practice 34: 321-326.

18. Kumei A, Nakayama H, Hasegawa M, Takaoka M (1991) An easier method of Mite fauna from house dust - Methylene Blue Agar (MBA) method for atopic dermatitis patients. Rinsho derm 33: 1531-1537.

19. Nakayama H (1989) Allergen control, an indispensable treatment for allergic contact dermatitis, Dermatol, Clinics 8: 197-204

20. Nakayama H, Matsuo S, Hayakawa K, Takhashi K, Shigematsu T, et al. (1984) Pigmented cosmetic dermatitis. Int J Dermatol 23: 299-305. [Crossref]

21. Aoki T (2001) Second report on the score of severity of atopic dermatitis - A committee report, Jap J Dermatol 111: 2023-2033 (In Japanese)

22. Costa C, Rilliet A, Nicolet M, Saurat JH (1989) Scoring atopic dermatitis: the simpler the better? Acta Derm Venereol 69: 41-45. [Crossref]

23. Kumei A (1995) Investigation of mites in the houses of atopic dermatitis (AD) patients, and clinical improvements by mite elimination Arerugi 44: 116-127. [Crossref] 
Nakayama H et al (2018) Mite Fauna Investigation Followed by Environmental Improvement Is Essential In Treating Intractable Atopic Dermatitis

24. Tan BB, Weald D, Strickland I, Friedmann PS (1996) Double-blind controlled trial of effect of housedust-mite allergen avoidance on atopic dermatitis Lancet 347: 15-18. [Crossref]

25. Nakayama H (2002) New aspects of metal allergy. Acta Dermatovenerol Croat 10 : 207-219. [Crossref]

26. Matsumura T, Ishii A (1993) Diseases due to animals and insects and international communication (Eds.,) Nakayama H, Shobunsha Kobe. Atopic dermatitis and mite allergy. Pp: $175-187$
27. Nakayama H, Kumei A (1998) Hifuka no Rinsho, Atopic Dermatitis, 40, Mite, 900901, Treatment by mite elimination $980-983$

28. Nakayama H, Kumei A, Ebihara T (1997) Effect of Environmental Improvement on Severe Cases of Atopic Dermatitis Skin Research 39: Supple 19: 94-102.

29. Shanon J (1965) Pseudo-atopic dermatitis. Contact dermatitis due to chrome sensitivity simulating atopic dermatitis Dermatologica 131: 176-190. [Crossref]

Copyright: $\odot 2018$ Rachidi M. This is an open-access article distributed under the terms of the Creative Commons Attribution License, which permits unrestricted use, distribution, and reproduction in any medium, provided the original author and source are credited. 